\title{
Circadian Blood Pressure Profile and Cardiovascular Risk Factors in Non-Dippers
}

\author{
Siti Suhaila MYa, Juwita $S^{a}$, Harmy MYa, Tengku Alina TI \\ a Department of Family Medicine, School of Medical Sciences, USM Health Campus, 16150 Kubang Kerian \\ Kelantan, Malaysia \\ ${ }^{b}$ Department of Community Medicine, School of Medical Sciences, USM Health Campus, 16150 Kubang Kerian \\ Kelantan, Malaysia
}

\begin{abstract}
Introduction: Ambulatory blood pressure accurately reflects a patient's actual blood pressure than casual or office blood pressure. This study aims to describe the circadian blood pressure profile of hypertensive patients and to identify the associated cardiovascular risk factors in non-dippers. Methods: A cross-sectional study was conducted from 1st January 2008 to 30th June 2008 among hypertensive patients attending Family Medicine Clinic HUSM. Schiller BR-102 plus was used to get 24 hours blood pressure (BP) reading. Mean of two offices BP were also taken. Non-dippers are defined as a systolic or diastolic nocturnal drop of less than $10 \%$. Analysis was done using SPSS Version 12. Results: 105 patients were recruited with mean (SD) age of 51.8 (9.34) year old. The mean (SD) 24-hour systolic and diastolic BP was 128.4 (12.7) $\mathrm{mmHg}$ and 79.7 (8.74) mmHg respectively. Mean (SD) daytime systolic and diastolic BP was $132.1(11.72) \mathrm{mmHg}$ and $82.4(9.41) \mathrm{mmHg}$ while for the night time were 123.3 (12.78) $\mathrm{mmHg}$ and 76.2 (9.01) $\mathrm{mmHg}$. Mean (SD) systolic and diastolic office BP was 144.2(15.16) $\mathrm{mmHg}$ and $90.2(9.71) \mathrm{mmHg}$. Percentage of non dippers were $68.6 \%$ for systolic and $61.9 \%$ for diastolic. Conclusion: Mean 24 hours and daytime ambulatory BP was normal but the mean night time diastolic and office BP was above-normal value. Majority of the patients were categorized as non dippers. Therefore, using ambulatory BP is clinically important to get a better understanding of blood pressure fluctuations over 24-hour periods compared to simple clinical measurements.
\end{abstract}

KEYWORDS: Ambulatory blood pressure monitoring, circadian blood pressure, nocturnal, cardiovascular risk factors

\section{INTRODUCTION}

Hypertension is a common and an important modifiable risk factor for cardiovascular disease, cerebrovascular and renal disease. Many clinical trials have confirmed that the risk of cardiovascular disease has decreased by treatment. ${ }^{1}$ In Malaysia, third National Health and Morbidity Survey (2006) showed that the prevalence of hypertension among adults above 30 years old was $43 \%$, a relative increase of $30 \%$ from 10 years earlier. Although the percentage of patients who are treated for hypertension has increased, the percentage of those who demonstrate control of blood pressure is declining. ${ }^{2}$

Corresponding author:

Dr Siti Suhaila Mohd Yusoff

Department of Family Medicine,

School of Medical Sciences,

Universiti Sains Malaysia Health Campus,

16150 Kubang Kerian, Kelantan,

Malaysia.

Tel: 609-7676608

Fax: 609-7676611

Email:drsuhaila@kk.usm.my
Studies confirmed that ambulatory blood pressure monitoring devices have accurately reflected a patient's actual blood pressure than casual or office BP and have correlated closely with end-organ complications. ${ }^{3,4}$ ABPM may improve the physician's ability to predict cardiovascular risk and may be particularly helpful in clinical situations such as borderline hypertension, white-coat hypertension, apparent drug resistance, hypotensive symptoms from medications or autonomic dysfunction, episodic hypertension, and the best possible use of ABPM data is to further evaluate and fine tune treatment in conjunction with in office pressure assessment. ${ }^{5}$

The presence of dip in nocturnal pressure may have prognostic implications. The absence of this decline which called non-dippers may place patients at an increasing risk of cardiovascular disease, particularly elderly patients. It also has been associated with increased risk of kidney and vascular target-organ injury compared with patients whose decline in blood pressure at night is normal and can be independent from the clinic, and 24-hour mean blood pressure values. ${ }^{6,7}$

This study looked at the circadian pattern of ambulatory blood pressure variation in hypertensive patients 
who attended the Family Medicine Clinic, Hospital Universiti Sains Malaysia (HUSM). The main aim was to explore the diurnal blood pressure and to identify the associated cardiovascular risk factors among nondippers.

\section{MATERIALS AND METHODS}

A total of 114 subjects were enrolled for this study. Subjects were identified according to the eligibility, hypertensive patient age 18 years and above, with stage I and II without target organ damage and were not pregnant. They were selected by systematic random sampling. All subjects were evaluated by detailed questionnaire and physical examination. The questionnaire provided information about sociodemographic and risk factors such as smoking status, past medical history, diabetes mellitus, and hypertension duration. The latest within three-month blood investigations such as fasting lipid profile and fasting blood sugar were documented. After 24-hours blood pressure monitoring, only 105 patients had adequate reading giving the response rate of $92 \%$. Nine patients were excluded because the ABPM readings were less than $80 \%$.

The study protocol was approved by the Research Ethics Committee, Universiti Sains Malaysia on 22 November 2006 [USM/PPSP/Ethics Com./2006 $(183.3(2)]$

\section{Research tool and ABPM measurement}

A twenty-four hour ABPM measurement were taken automatically at the non-dominant arm by an oscillometric portable monitor Schiller BR-102. The device was evaluated using the protocols of the British Hypertension Society and the US Association for the Advancement of Medical Instrumentation.

Day and night have been defined as the waking and sleeping periods from the patient's diary but in this study, a wide fixed time interval was used as day-andnight blood pressure. ${ }^{8}$ Daytime was defined from 0601 to 2200 and night time was defined between 2201 to $0600 \mathrm{hr}$. All the patients were advised to maintain their daily activities and avoid vigorous exercise during the ABPM. The tools were programmed for reading every 60 minutes from 0600 to 2200 and every 120 minutes from 2201 to 2359 because of sleeping time then every 30 minutes from 2400 to $0600 \mathrm{hr}$. The recordings from the monitor were downloaded to a PC-compatible by using the MT-300 program, and it displayed all the readings values for systolic and diastolic BP.

\section{Day and night blood pressure variation}

From the mean daytime and night-time blood pressure, the percentage of nocturnal decline of systolic blood pressure (SBP) and diastolic blood pressure (DBP) was calculated as: [(mean daytime BP-mean night time BP)/mean daytime BP]x100 (normal $\geq 10 \%$ ). The hypertensive patients can be defined as 'dippers' when the average nocturnal BP decreases by $>10 \%$ of average daytime BP and as 'non-dippers' when the decrease is $<10 \%$ of daytime BP (O'Brien E et al., 1988). ${ }^{9}$ In this study, both systolic and diastolic dippers and non-dippers were calculated using the above formula.

\section{Statistics}

Data entry and analysis were conducted using SPSS for Windows version 12.0. Data exploration was done including descriptive statistics and appropriate graphs for each variable. Quantitative variables are expressed as mean values and standard deviation (SD) and qualitative variables are expressed as frequency and percentage (\%).

From this analysis, the daytime systolic blood pressure (day SBP), daytime diastolic blood pressure (day DBP), night systolic blood pressure (night SBP), night diastolic blood pressure (night DBP), average 24 hours systolic blood pressure (24 SBP), average of all blood pressure profile as well as the percentage of dippers and non-dippers were obtained.

The analysis continued with simple logistic regressions to determine the associated cardiovascular risk factor for systolic and diastolic non-dippers as the outcome. Simple logistic regression was used as a screening in selection of variables for further step of analysis. It was then followed by a multiple logistic regression analysis for the factors with the $p$-value of less than 0.3 and factors that has clinical significant. This $p$ value was set larger than the level of significance to allow for more important variables to be included in the model. The method used for variable selection was backward and forward stepwise procedure. A value of $p<0.05$ was considered as statistically significant.

\section{RESULTS}

\section{Demographic data}

The study population consists of 59 men, and 46 women with mean age of $51.8 \pm(9.3)$ years. Majority of them were not smoker or already quitted for more than 6 months. The hypertension duration ranges from one month to 8 years and they were on one to four anti-hypertensive medication. Table la and Ib shows the details of demographic and clinical characteristic of 104 respondents. 
TABLES

Table la. Socio-demographic data of 105 hypertensive patients

\begin{tabular}{|c|c|c|c|c|}
\hline $\begin{array}{l}\text { Characteristics } \\
\mathrm{n}=105\end{array}$ & Mean & $(\mathrm{SD})$ & $\mathrm{n}$ & $(\%)$ \\
\hline Age (year) & 51.8 & 9.34 & & \\
\hline \multicolumn{5}{|l|}{ Race } \\
\hline Malay & & & 91 & 86.7 \\
\hline Chinese & & & 14 & 13.3 \\
\hline \multicolumn{5}{|l|}{ Gender } \\
\hline Male & & & 59 & 56.2 \\
\hline Female & & & 46 & 43.8 \\
\hline \multicolumn{5}{|l|}{ Occupation } \\
\hline Unemployed & & & 62 & 43 \\
\hline Employed & & & 59.0 & 41.0 \\
\hline \multicolumn{5}{|l|}{ Smoking } \\
\hline No & & & 67 & 63.8 \\
\hline Yes & & & 38 & 36.2 \\
\hline
\end{tabular}

Table Ib. Clinical characteristicsof 105 hypertensive patients

\begin{tabular}{|c|c|c|c|c|}
\hline $\begin{array}{l}\text { Characteristic } \\
n=105\end{array}$ & Mean & $(S D)$ & $\mathrm{n}$ & $(\%)$ \\
\hline Duration of hypertension & 4.2 & $(3.94)$ & & \\
\hline Number of antihypertensive & 1.6 & $(0.65)$ & & \\
\hline \multicolumn{5}{|l|}{ Diabetes Mellitus } \\
\hline No & & & 86 & (81.9) \\
\hline Yes & & & 19 & (18.1) \\
\hline \multicolumn{5}{|l|}{ Body Mass Index (kg/m2) } \\
\hline Normal BMI & & & 13 & (12.4) \\
\hline Overweight & & & 92 & $(87.6)$ \\
\hline \multicolumn{5}{|l|}{ Waist Circumference (cm) } \\
\hline Normal WC & & & 29 & $(27.6)$ \\
\hline Abnormal WC & & & 76 & $(72.4)$ \\
\hline \multicolumn{5}{|l|}{ Total Cholesterol (mmol/L) } \\
\hline Normal TC & & & 12 & $(11.4)$ \\
\hline Abnormal TC & & & 93 & $(88.6)$ \\
\hline HDL (mmol/L) & 1.4 & $(0.37)$ & & \\
\hline LDL (mmol/L) & 3.5 & $(1.03)$ & & \\
\hline TG (mmol/L) & 1.7 & $(0.85)$ & & \\
\hline
\end{tabular}

Table II shows the blood pressure profile based on ambulatory blood pressure monitoring. The mean (SD) of 24 hours systolic blood pressure (SBP) and diastolic blood pressure (DBP) were $128.5 \pm(11.52) \mathrm{mmHg}$ and
$79.8(\mathrm{SD} \pm 8.74) \mathrm{mmHg}$ respectively. Figure 1 shows the percentage for nocturnal fall (dippers) in SBP was $31.4 \%$ while for dippers in DBP was $38.1 \%$. 
Table II. Blood pressure profile based on ambulatory blood pressure monitoring

\begin{tabular}{llll}
\hline & & $\begin{array}{l}\text { Systolic } \\
\text { Mean (SD) }\end{array}$ & $\begin{array}{l}\text { Diastolic } \\
\text { Mean (SD) }\end{array}$ \\
\hline ABPM & Daytime & $132.2(11.72)$ & $82.4(9.41)$ \\
& Nighttime & $123.4(12.78)$ & $76.2(9.01)$ \\
& 24 Hour & $128.5(11.52)$ & $79.8(8.74)$ \\
\hline
\end{tabular}

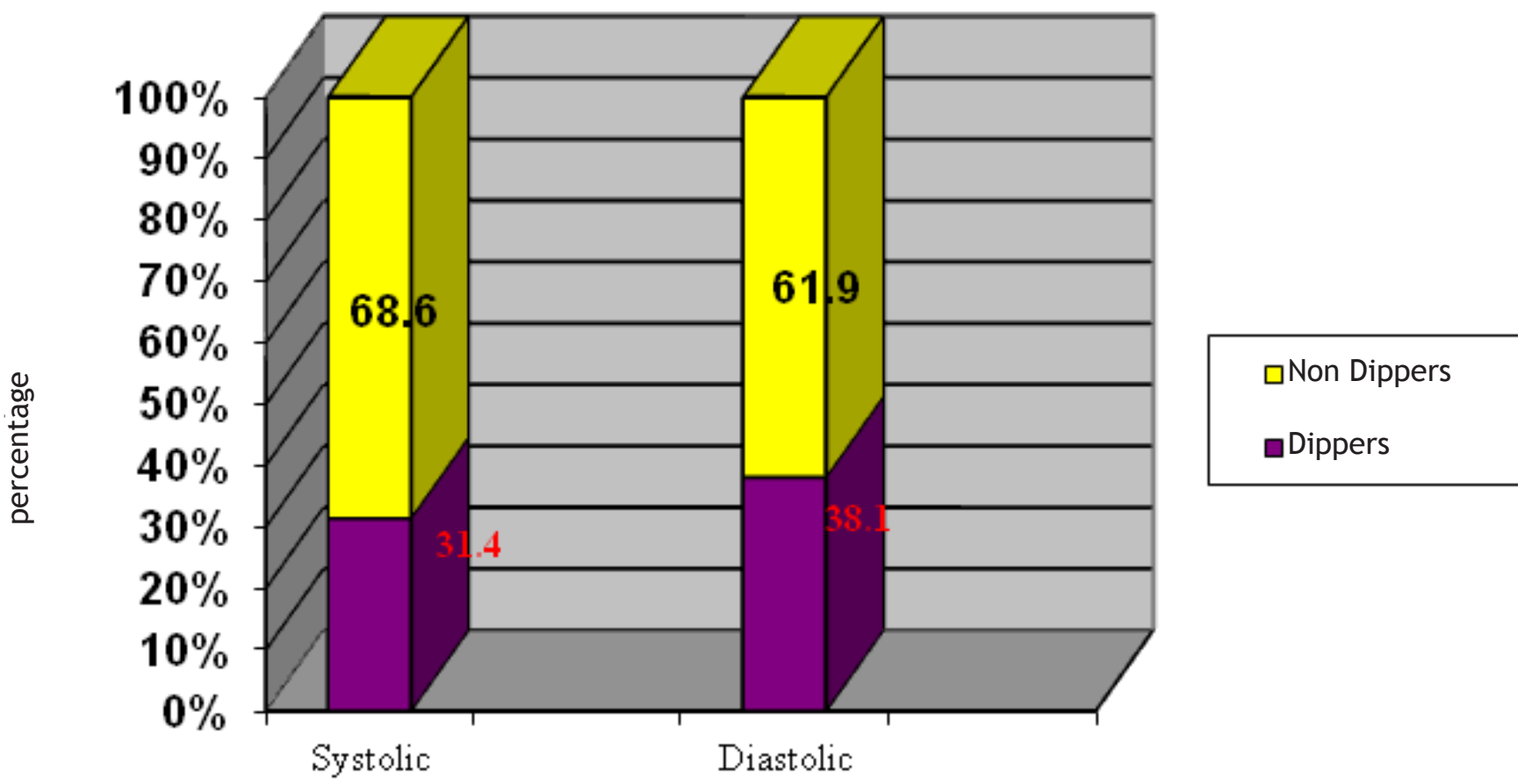

Figure 1. Percentage of Dippers and Non-dippers of 105 hypertensive patients

Table III and IV shows analysis using simple and of cardiovascular risk with the non-dippers. No multiple logistic regressions, to look for the association significant $(p>0.05)$ finding was noted. 
Table III. Simple logistic regression analysis to determine the associated factors for systolic non-dippers

\begin{tabular}{|c|c|c|c|c|c|c|}
\hline \multirow[b]{2}{*}{ Factors } & \multicolumn{2}{|c|}{ Systolic non-dippers } & \multirow{2}{*}{$\begin{array}{l}\text { Crude } \\
O R^{\mathrm{a}}\end{array}$} & \multirow[b]{2}{*}{$95 \% \mathrm{Cl}^{\mathrm{b}}$} & \multirow[b]{2}{*}{ wald } & \multirow[b]{2}{*}{$\mathrm{p}$-value } \\
\hline & $\begin{array}{l}\text { Yes } \\
\text { n (\%) }\end{array}$ & $\begin{array}{l}\text { No } \\
\mathrm{n}(\%)\end{array}$ & & & & \\
\hline \multicolumn{7}{|l|}{$\operatorname{Age}(M \geq 55$ years $)$} \\
\hline \multicolumn{7}{|l|}{$(F \geq 65$ years $)$} \\
\hline No & $31(43.05)$ & $12(36.36)$ & 1.00 & & & \\
\hline Yes & $41(56.64)$ & $21(63.64)$ & 0.76 & $0.32,1.77$ & 0.42 & 0.518 \\
\hline \multicolumn{7}{|l|}{ Gender } \\
\hline Male & $39(54.17)$ & $20(60.61)$ & 1.00 & & & \\
\hline Female & $33(45.83)$ & 13(39.39) & 1.30 & $0.56,3.01$ & 0.38 & 0.537 \\
\hline \multicolumn{7}{|l|}{ Smoking } \\
\hline No & $44(61.11)$ & $23(69.70)$ & 1.00 & & & \\
\hline Yes & $28(38.89)$ & $10(30.30)$ & 1.46 & $0.61,3.53$ & 0.73 & 0.392 \\
\hline \multicolumn{7}{|l|}{ Diabetes } \\
\hline No & $57(79.17)$ & $29(87.88)$ & 1.00 & & & \\
\hline Yes & $15(20.83)$ & $4(12.12)$ & 1.90 & $0.58,6.27$ & 1.13 & 0.287 \\
\hline \multicolumn{7}{|l|}{ Overweight (kg/m2) } \\
\hline No & $9(12.50)$ & $4(12.12)$ & 1.00 & & & \\
\hline Yes & $63(87.50)$ & $29(87.88)$ & 0.97 & $0.27,3.39$ & 0.00 & 0.956 \\
\hline \multicolumn{7}{|l|}{ Increase waist } \\
\hline \multicolumn{7}{|l|}{ Circumference $(\mathrm{cm})$} \\
\hline No & $16(22.22)$ & $13(39.40)$ & 1.00 & & & \\
\hline Yes & $56(77.78)$ & $20(60.60)$ & 2.28 & $0.93,5.55$ & 3.26 & 0.071 \\
\hline $\mathrm{HDL}(\mathrm{mmol} / \mathrm{L})$ & $1.44^{c}(0.41)^{d}$ & $1.35^{c}(0.31)^{d}$ & 1.87 & $0.59,5.90$ & 1.14 & 0.285 \\
\hline $\mathrm{LDL}(\mathrm{mmol} / \mathrm{L})$ & $3.40^{c}(1.06)^{d}$ & $3.69^{c}(0.98)^{d}$ & 0.76 & $0.51,1.14$ & 1.75 & 0.186 \\
\hline $\mathrm{TG}(\mathrm{mmol} / \mathrm{L})$ & $1.64^{c}(0.85)^{d}$ & $1.77^{c}(0.87)^{d}$ & 0.84 & $0.53,1.35$ & 0.49 & 0.483 \\
\hline \multicolumn{7}{|c|}{ High Cholesterol (mmol/L) } \\
\hline No & $9(12.50)$ & $3(9.09)$ & & & & \\
\hline Yes & $63(87.50)$ & $30(90.91)$ & 0.70 & $0.17,2.77$ & 0.26 & 0.612 \\
\hline
\end{tabular}

${ }^{\mathrm{a} O R}=$ Odds Ratio, ${ }^{\mathrm{b}} \mathrm{Cl}=$ Confidence Interval, ${ }^{\mathrm{c}}$ mean, ${ }^{\mathrm{d}} \mathrm{SD}$ 
Table IV. Simple logistic regression analysis to determine the associated factors for diastolic non-dippers.

\begin{tabular}{|c|c|c|c|c|c|c|}
\hline \multirow[b]{3}{*}{ Factors } & \multicolumn{2}{|c|}{ Diastolic non dippers } & \multirow{3}{*}{$\begin{array}{l}\text { Crude } \\
\mathrm{OR}^{\mathrm{a}}\end{array}$} & \multirow{3}{*}{$95 \% \mathrm{Cl}^{\mathrm{b}}$} & \multirow{3}{*}{ wald } & \multirow{3}{*}{$p$-value } \\
\hline & Yes & No & & & & \\
\hline & Freq (\%) & Freq $(\%)$ & & & & \\
\hline \multicolumn{7}{|l|}{$\operatorname{Age}(M \geq 55$ years $)$} \\
\hline \multicolumn{7}{|l|}{$(F \geq 65$ years $)$} \\
\hline No & $29(44.62)$ & $14(35.00)$ & 1.00 & & & \\
\hline Yes & $36(55.38)$ & $26(65.00)$ & 0.67 & $0.29,1.50$ & 0.94 & 0.332 \\
\hline \multicolumn{7}{|l|}{ Gender } \\
\hline Male & $36(55.38)$ & $23(57.50)$ & 1.00 & & & \\
\hline Female & $29(44.62)$ & $17(42.50)$ & 1.09 & $0.49,2.41$ & 0.05 & 0.832 \\
\hline \multicolumn{7}{|l|}{ Smoking } \\
\hline No & $41(63.08)$ & $26(65.00)$ & 1.00 & & & \\
\hline Yes & $24(36.92)$ & $14(35.00)$ & 1.08 & $0.48,2.47$ & 0.04 & 0.842 \\
\hline \multicolumn{7}{|l|}{ Diabetes } \\
\hline No & $52(80.00)$ & $34(85.00)$ & 1.00 & & & \\
\hline Yes & $13(20.00)$ & $6(15.00)$ & 1.41 & $0.49,4.08$ & 0.42 & 0.519 \\
\hline \multicolumn{7}{|c|}{ Overweight $(\mathrm{kg} / \mathrm{m} 2)$} \\
\hline No & $7(10.77)$ & $6(15.00)$ & 1.00 & & & \\
\hline Yes & $58(89.23)$ & $34(85.00)$ & 1.46 & $0.45,4.71$ & 0.40 & 0.524 \\
\hline \multicolumn{7}{|l|}{ Increase waist } \\
\hline \multicolumn{7}{|l|}{ Circumference $(\mathrm{cm})$} \\
\hline No & $16(24.62)$ & $13(32.50)$ & 1.00 & & & \\
\hline Yes & $49(75.38)$ & $27(67.50)$ & 1.47 & $0.62,3.52$ & 0.77 & 0.381 \\
\hline $\mathrm{HDL}(\mathrm{mmol} / / \mathrm{L})$ & $1.4^{\mathrm{c}}(0.36)^{\mathrm{d}}$ & $1.4^{c}(0.411)^{d}$ & 1.65 & $0.56,4.85$ & 0.83 & 0.362 \\
\hline LDL (mmol//L) & $3.5^{\mathrm{c}}(0.99)^{\mathrm{d}}$ & $3.5^{c}(1.12)^{d}$ & 1.01 & $0.69,1.48$ & 0.00 & 0.952 \\
\hline TG (mmol//L) & $1.7^{c}(0.93)^{d}$ & $1.7^{c}(0.73)^{d}$ & 0.96 & $0.60,1.51$ & 0.03 & 0.856 \\
\hline \multicolumn{7}{|l|}{$\begin{array}{l}\text { High Cholesterol } \\
\text { (mmol//L) }\end{array}$} \\
\hline No & $5(7.69)$ & $7(17.50)$ & 1.00 & & & \\
\hline Yes & $60(92.31)$ & $33(82.50)$ & 2.54 & $0.75,8.65$ & 2.24 & 0.135 \\
\hline
\end{tabular}

${ }^{\mathrm{a} O R}=$ Odds Ratio, ${ }^{\mathrm{b}} \mathrm{Cl}=$ Confidence Interval, ${ }^{\mathrm{c}}$ mean, ${ }^{\mathrm{d} S \mathrm{~S}}$ 


\section{DISCUSSION}

ABPM devices allow a better understanding of circadianor fluctuation of blood pressure measurements. It will help to detect and distinguish the status of the dippers and the non-dippers.

There are many studies with different value of normal ambulatory blood pressure monitoring (ABPM). The American Heart Association recommended standard value or references for abnormal pressures during ambulatory measurement ie more than $140 / 90$ $\mathrm{mmHg}$ for daytime, more than $125 / 75 \mathrm{mmHg}$ for night time and more than $135 / 85 \mathrm{mmHg}$ for 24 hours blood pressure. ${ }^{10,11}$ These figures are only a guide, and lower pressures may be abnormal in patient whose total risk factor profile is high and in whom there is a concomitant disease. ${ }^{12}$

In this study, we found the blood pressure pattern of daytime and 24 hours were in the normal range. Even though our patients were at middle age, their mean 24-hour systolic blood pressure (SBP) and diastolic blood pressure (DBP) were in a good range (128.45 / $79.79 \mathrm{mmHg}$ ), implying these patients had a reasonably well controlled BP. These results may also be used to indicate optimum control of patients under follow up in the clinic set up, which can be used as an audit tool.

However, the mean night time BP was 123.15 / 76.22 $\mathrm{mmHg}$, which means that the diastolic BP was slightly higher compared to the normal value of the night-time ABPM reading at DBP $\leq 75 \mathrm{mmHg} .{ }^{10}$ There are several reasons of having high mean night time blood pressure in this study that would also contribute to the high percentage of non-dippers in this population. One of them was due to the use of a wide fixed time interval (6-22h) for daytime and (22-6h) for night time in this study in which we could not get the actual sleeping time of each patient. According to Fagard et al., short fixed time period to define the night time was preferred to get proper night time blood pressure, for instance from midnight to $6 \mathrm{am}$, thereby excluding to a large extent overlapping periods that patients may be either awake or have gone to bed. ${ }^{13}$

Frequent cuff inflations also could disturb sleep with consequent possibility for overestimation of the nighttime BP in this study. Therefore, it is important to know the quality of sleep during the blood pressure monitoring. Some literature also stated that BP variations may be associated with sleep quality, emotions as well as physical activity. Kario et al. did a study on the associations between depression, anxiety, awake physical activity, sleep quality and diurnal blood pressure variation in the non-psychiatric sample. ${ }^{14}$ They found that depression is associated with abnormal diurnal pattern independent of physical activity in working men, and anxiety is associated with awake SBP in women. ${ }^{14}$ However, in this study, we did not evaluate the psychological factors that might contribute to the high blood pressure in this population. In a study by Mohamed AL, ${ }^{15}$ they found that all the BP measurements using ambulatory blood pressure were normal among primary hypertension, but their population was younger with mean age was 38.19 (SD 11.7) compared to our study with mean age of 51.8 (SD 9.3) which indicate the uncontrolled hypertension increased with increasing age.

The mean night time diastolic BP was high in this population, which indicate that they are at a potentially higher risk. A few studies showed that night-time blood pressure was an independent predictor of total cardiac and cerebrovascular events..$^{16-18}$ The night time blood pressure is a better prognostic value than the daytime blood pressure. ${ }^{19}$ Therefore, the follow up and modification of their medication to achieve a better controlled blood pressure is important.

In people with normal BP and in most hypertensive patients, the BP dips by $10 \%$ to $20 \%$ at night. "Nondippers" i.e. people whose blood pressure does not dip or dips very little during the sleep or characterized by the loss or even reversal of the expected $10 \%$ to $20 \%$ sleep time BP decline, is associated with elevated risk of end-organ injury, particularlyto the heart (left ventricular hypertrophy and myocardial infarct), brain (stroke) and kidney (albuminuria and progression to end-stagerenal failure). $7,17,20,21$ Non-dipper's BP is more frequent in secondary hypertension than in uncomplicated primary hypertension. ${ }^{22}$

Majority of our respondents were categorized as the non-dippers with $68.6 \%$ of systolic and $61.9 \%$ of diastolic pressure. The prevalence of the non-dippers in our study was quite similar to a study done by Tartan et al., which found that $61.4 \%$ among hypertensive patients were the non-dippers. ${ }^{23}$

From the literature, there are several factors that contribute to the non-dippers and abnormal night-time blood pressure. Non-dipper's BP patterning is more frequent in hypertension that is secondary to specific medical conditions, such as chronic renal failure, diabetes, and autonomic nervous system dysfunction than in uncomplicated primary hypertension. ${ }^{24}$ The literature also states that the timing and amplitude of the natural rhythm of BP is influenced by the neurohormonal regulation, but the effect of extrinsic factors, such as physical activity and dietary sodium, may be of greater significance. Additionally, behavioral influences, such as mental activity and emotional state, and lifestyle factors, such as smoking cigarettes and drinking alcohol, can also affect the natural rhythm of BP. ${ }^{25}$

In this study we did not evaluate the detail information of all the above activity so we were unable to get the reason of having high percentage of abnormal night time blood pressure and the non-dippers. Other causes of the non-dippers include autonomic dysfunction syndromes, diabetes (with neuropathy and/or nephropathy), renal insufficiency, pheochromocytoma, 
Cushing's syndrome, primary-aldosteronism, some drugs, as well as severe systolic hypertension in the elderly. ${ }^{26}$

Other studies concluded that higher prevalence of the non-dipper was contributed by the time when the antihypertensive treatment was taken. There was a marked reduction in the ambulatory blood pressure, mainly during the hours of nocturnal rest, when patients with resistant hypertension were treated with one drug at bedtime..$^{27,28}$ However, we also have no data to evaluate the time of antihypertensive taken. Furthermore, ambulatory blood pressure monitoring was done only for 24 hours compared to their study which used ABPM for 48 hours to confirm the accurate prevalence of the non-dippers in their population.

This study shows that the association of cardiovascular risk factors among the non-dippers was insignificant. The reason of this insignificant result could be due to the cross-sectional study design which is unsuitable to look for the associated factors. It is more appropriate to do a cohort study to look for relevant markers of end organ damage and cardiovascular mortality, namely plasma glucose, total cholesterol, LDL cholesterol, and urinary albumin excretion. However, a study by Tartan et al., ${ }^{23}$ showed significant relationship between increasing MS-Score and all systolic blood pressure, particularly nighttime SBP with non-dippers. Their study differs from ours as their populations suffered from metabolic syndromes.

\section{CONCLUSION}

Majority of the hypertensive patients had a controlled ambulatory BP except for the night time and office blood pressure. The overall percentage of the nondippers in this study was high, however, the association of cardiovascular risk among the non-dippers was found to be insignificant.

Ambulatory blood pressure monitoring is patient dependent and requires patient's commitment to wear the device for 24 hours in order to get accurate reading. However, most of the patients are unable to do so as the majorities are Malays and Muslims, and they have to remove the device at each prayer time or when they want to take a shower. The use of a single measurement of ABPM can result in over estimation of its prevalence of dippers and non-dippers as well as the underestimation of the true percentage of the non-dippers.

\section{CONFLICT OF INTEREST}

There is no commercial association that may create a conflict of interest in connection with this submitted manuscript. All authors are affiliated with the Universiti Sains Malaysia and receive no financial benefit from the publication of this study.

\section{ACKNOWLEDGEMENTS}

We would like to convey a very special thank you and appreciation to Professor Abdul Rashid Abdul Rahman, who supported and always there to answer my enquiries even during short meetings.

\section{REFERENCES}

1. Spencer C, Lip G. Hypertension (1) Epidemiology and risks. Pharmaceutical Journal 1999; 263: 280-3.

2. Institute for Public Health (IPH) 2008. The third National Health Survey (NHMS III) 2006, Vol 2. Ministry of Health Malaysia.

3. Godwin M, Delva D, Sequin R, et al. Relationship between blood pressure measurements recorded on patients' charts in family physicians' offices and subsequent 24 hour ambulatory blood pressure monitoring. BMC Cardiovasc Disord 2004; 4:2.

4. Kandiah N, Rampal L, Paranjothy G. Gill AK. A community based study on the epidemiology of hypertension in Selangor. Med J Malaysia 1980; 34:211-20.

5. O'Brien E, Beevers G, Lip GY. ABC of hypertension. Blood pressure measurement. Part III-automated sphygmomanometry: ambulatory blood pressure measurement. BMJ 2001; 322:1110-4.

6. Verdecchia P, Fabio A, Roberto G. Clinical usefulness of ambulatory blood pressure monitoring. J Am Soc Nephrol 2004;15:30-33.

7. White WB. Ambulatory blood pressure monitoring: dippers compared with non-dippers. Blood Press Monit 2000; 5:17-23.

8. Verdecchia P. Prognostic value of ambulatory blood pressure: current evidence and clinical implications. Hypertension 2000; 35:844-51.

9. O’Brien E, Sheridan J, O'Malley K. Dippers and Non-dippers. Lancet 1988; 2:397.

10. O’Brien E, Andrew C, Patrick O, et al. Use and interpretation of ambulatory blood pressure monitoring: recommendation of the British Hypertension Society. BMJ 2000;320: 1128-34.

11. Pickering TG. The clinical significance of diurnal blood pressure variations. Dippers and Non dippers. Circulation 1990; 81:700-2.

12. Pickering TG. Ambulatory blood pressure monitoring in clinical practice. Clin Cardiol 1991; 14:557-62.

13. Fagard R, Staessen J, Thijs L. Optimal definition of daytime and night-time blood pressure. Blood Press Monit 1997; 2:315-21.

14. Kario K, Schwartz JE, Davidson K, Pickering T. Gender differences in associations of diurnal blood pressure variation, awake physical activity, and sleep quality with negative affect: The work site blood pressure study. Hypertension 2001; 38:997-1002.

15. Mohamed AL, E Katiman, J Abu Hassan. Ambulatory blood pressure monitoring as a useful prognostic tool in patients with primary hypertension. Malays J Med Sci 2003; 10:76-83. 
16. Esposti ED, Martino MD, Sturani A, et al. Risk factors for uncontrolled hypertension in Italy. J Hum Hypertens 2004; 18:207-13.

17. Staessen JA, Thijs L, Fagard R, et al. Systolic hypertension in Europe (Syst-Eur) trial investigators. Predicting cardiovascular risk using conventional vs ambulatory blood pressure in older patients with systolic hypertension. J Am Med Assoc 1999; 282:539-46.

18. Burr ML, Dolan E, O'Brien EW, O'Brien ET, McCormack P. The value of ambulatory blood pressure in older adults: the Dublin study. Age Ageing 2008; 37:201-6.

19. Kikuya M, Ohkubo T, Asayama K, et al. Ambulatory blood pressure and 10 -Year risk of cardiovascular and noncardiovascular mortality: the Ohasama study. Hypertension 2004; 45: 240-5.

20. Verdecchia P, Porcellati C, Schillaci G, et al. Ambulatory blood pressure: an independent predictor of prognosis in essential hypertension. Hypertension 1994; 24:793-801.

21. Morgan TO. Is non-dipping status a predictor of cardiac morbidity? J Hypertens 2002; 20:1469-71.

22. Hermida RC, Ayala DE, Fernandez JR, et al. Modeling the circadian variability of ambulatory monitored blood pressure by multiple-component analysis. Chronobiol Int 2002; 19:461-81.

23. Tartan Z, Uyarel H, Kasikcioglu H, et al. Metabolic syndromes as a predictor of nondipping hypertension. Tohoku J Exp Med 2006; 210: 57-66.

24. Hermida RC, Ayala DE, Calvo C, et al. Effects of time of day of treatment on ambulatory blood pressure pattern of patients with resistant hypertension. Hypertension 2005; 46: 1053-9.

25. Pickering TG, James GD. Determinants and consequences of the diurnal rhythm of blood pressure. Am J Hypertens 1993; 6:66-9.

26. Giles TD. Circadian rhythm of blood pressure and the relation to cardiovascular events. J Hypertens 2006; 24:11-6.

27. Hermida RC, Fernández JR, Mojón A, Ayala DE. Reproducibility of the hyperbaric index as a measure of blood pressure excess. Hypertension 2005; 35:118-25.

28. Muxfeldt ES, Bloch KV, Nogueira AR, Salles GF. Twenty four hour ambulatory blood pressure monitoring pattern of resistant hypertension. Blood Press Monit 2003; 8:181-5. 